\section{NO Place \\ for a Woman}

\section{Or a physicist?}

The Athenaeum is a club for gentlemen. And so when Franklin, being no gentleman at all, turned up for a visit recently without a tie, he was forced to wait on the steps until his rendezvous had arrived.

The club is not for the average gentleman. It's been there for 168 years. Humphry Davy was its first chairman, and Michael Faraday its first secretary (Davy needed a good secretary because he had damaged his eyes investigating acids). The following were all members: Max Beerbohm, Lord Blackett, William Bragg, James Chadwick, John Herschel, James Jeans, Lord Kelvin, Lord Rayleigh, Lord Snell and Niels Bohr, not to mention botanists Charles Darwin and Joseph Hooker, surgeon Lord Lister and politician William Churchill. When it was founded, the first rule was that "no one should be eligible except gentlemen". And the second rule was that they should be distinguished in cultural life.

But actually the club was partly founded because Faraday and others were annoyed at Joseph Banks, who was part of an older generation that had ruled the roost at the Royal Society for many years - the Athenaeum was the club for the younger Victorian scientist.

When you walk to the club from the London Underground at Piccadilly you walk down onto Pall Mall - the club rises in the heart of 'gentlemen' London - where the Royal Society, the UK's most prestigious society of eminent scientists, is just round the corner; Buckingham Palace is a short walk away; and the Cabinet War rooms, from which the British government fought World War II, are just a stone's throw away.

A golden statue of Athenee, in front of a freeze of the Parthenon, confronts you as you approach. It stands on top of four stone pillars, underneath which rise the stone steps on which improperly dressed guests have to wait - the entrance to the club is guarded by a porter's lodge at which guests must report before being allowed inside.

Once an escort arrives, though, entry is no problem.

Franklin's guide was the club's librarian, Sarah Dodgson. The interior is decorated in the style of the 1840 s - the rooms were re- decorated in the 1980 s returning them almost to their original fashion. There is a grand staircase and plenty of large portraits (of course), but also a spectacularly large dining room and a library with twisting iron staircases and leather-bound books that creak as you walk round. There is also a coffin-shaped lift. When they turned some of the rooms into bedrooms for members they installed a lift that could easily hold a coffin incase a distinguished guest passed away in the night.

And just outside the bedrooms is a physicist's relic: Faraday's wooden wheelchair, which looks hard and uncomfortable but was (apparently) used by Faraday for many years.

But Franklin had really come to see the inner sanctuary, on the ground floor. It has green-leather studded armchairs, newspapers and a coffee bar. It looks the perfect place for any Victorian gentlemen to retreat to in the evening for a quiet smoke. But when Victorian gentlemen retreated from dinner in the evening, it was without female company. And indeed women are not allowed in the inner sanctuary of this club. Ever.

Women are not allowed to join the club, either. This is not a strange feature of English culture. There are other clubs in London with similar rules. And it's an issue that has been hotly debated in England in recent years. But Franklin is always a curious fellow, and recently asked the opinion on this of one of its members. The member in question wasn't keen to talk about the club at all.

That Athenaeum member was the Chief Executive of the Institute of Physics (IoP), Alun Jones. Franklin was curious to get his opinion, because the IoP has an equal opportunities policy when it comes to hiring staff: men and women get an equal chance of getting the position.

Franklin has no criticism of the way Jones has run the IoP. Indeed this year the IoP appointed a hard-working and able woman as student liaison office. But Jones is a member of a prestigious men-only club, and Franklin thinks this is not commensurate with running an organisation with an equal opportunities policy. It's simply that Jones spends some of his time in an environment in which there are more opportunities if you are male. A too Victorian way of life.

Do you agree with Franklin? Reply to Franklin, c/o European Physical Society, 34 rue Marc Seguin, F-68060 Mulhouse, France; or send an e-mail to eneditor@univ-mulhouse.fr
If you have any job vacancies why not advertise them in

\section{europhysics news}

Reach over 26.000 physicists and related professionals in almost every field in Europe without wasting your budget on the wrong audience! \section{Springer}

Mr. Stefan Kindt

Phone $+49 / 30 / 82787-741$

Fax $\quad+49 / 30 / 82787-300$

e-mail anzeigen@springer.de 